\title{
Preliminary Phytochemical Screening and Antifungal Activity of Bilimbi and Papaya Leaf Extract on Fungal Pathogens
}

\author{
Chinju Merin Abraham ${ }^{*}$, Soumya Prasad ${ }^{2}$ \\ ${ }^{1}$ Dep. of Botany, Catholicate College, Pathanamthitta, Kerala, India - 689645 \\ ${ }^{2}$ Dep. of Botany, Catholicate College, Pathanamthitta, India. \\ *Corresponding Author: chinjujoby@gmail.com,Tel.:+91-9846129284
}

Available online at: www.isroset.org

Accepted: 17/Aug/2018, Online: 30/Aug/ 2018

\begin{abstract}
The present study has witnessed the phytochemical and antifungal property of bilimbi and papaya aqueous leaf extracts. Through the preliminary phytochemical screening, bilimbi leaf extract indicated the presence of flavonoids, saponins, coumarins, steroids and papaya leaf extract indicated the presence of terpenoids, saponins, coumarins and steroids. We isolated and identified fungal pathogens from root and seed of paddy plant inoculated on PDA medium. Disc diffusion method was used to measure the antifungal property of leaf extracts on 3 selected fungal genera such as Cylindrocarpon, Penicillium and Curvularia which were used as test organism. The extracts having antimicrobial activity has varied diameter of zone of inhibition among the tested organisms. Bilimbi leaf extract has antifungal activity against Cylindrocarpon, Penicillium with zone of inhibition of $10 \mathrm{~mm}$, and $5 \mathrm{~mm}$ respectively and no markable activity against Curvularia. Papaya leaf extract has antifungal activity against Cylindrocarpon, Penicillium and Curvularia with zone of inhibition of $12 \mathrm{~mm}, 5 \mathrm{~mm}$ and $15 \mathrm{~mm}$ respectively. The highest level of antifungal activity was recorded in papaya leaf extract which was active against all tested organisms that may be due to the presence of different types of phytochemicals. Plant metabolites are strong candidate contribute to develop new leads, combat the emerging issues of drug resistance.
\end{abstract}

Keywords- Aqueous leaf extract, Phytochemicals, Antifungal activity, Disc diffusion, Bilimbi, Papaya.

\section{INTRODUCTION}

Fungi are one among the most widely distributed organisms on earth. Many crops are attacked and destroyed by fungal pathogens. Thousands of diseases are known and many more are yet to be discovered by the mycologists and plant pathologists [1]. The common plant fungal diseases include smuts, rusts, mildews, blights, rots and wilts. The mycotoxins produced by fungal pathogens can cause serious ill-effects like aspergillosis, zygomycosis, occupational asthma, mucormycosis etc [2].

Need and use of antifungal agents for various purposes are very important in this context. Chemical fungicides have often been used to control plant disease, but this method is associated with negative environmental impacts such as potential human exposure to pesticides and deposition of residues on the fruits. For this reason alternative methods of reducing pesticide are being developed. New antifungal compounds with distinct modes of action need to be identified [3]. One of the effective methods is to use plant extracts which provides natural anti-fungal substances.

Plant secondary metabolites have great potential as a source of antifungal agents [4]. So scientist can develop new molecules using useful plant metabolites. This emphasizes the importance of the present work. The study revealed the phytochemical and antifungal property of bilimbi and papaya aqueous leaf extracts. Through disc diffusion method and by measuring the diameter of zone of inhibition it was clear that leaf extract was active against all tested fungal pathogens and that may be due to the presence different phytochemicals.

\section{MATERIALS AND METHODS}

Plant materials used for the study includes Oryza sativa (paddy) seed and root for fungal isolation and leaves of Averrhoa bilimbi (bilimbi) and Carica papaya (papaya) for phytochemical screening and antifungal testing.

1. Phytochemical screening of leaf extract: 
Aqueous leaf extracts of bilimbi and papaya were subjected to phytochemical screening for the presence of different bioactive components. Plants contain a rich source of phytochemicals such as, saponins, flavonoids, tannins, steroids, anthraquinones, quinines, phenols, proteins, coumarins and alkaloids [5].

Collection of plant material:

Collected plants were identified using standard herbarium available in Catholicate College, Pathanamthitta and their leaves were used for further study.

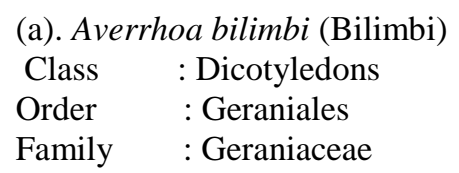

Bilimbi is a small tree which grows up to $15 \mathrm{~m}$ high with sparsely arranged branches. It has compound leaves with 20 - 40 leaflets each and 5-10 cm long [6].The leaves are hairy with pinnate shapes and form clusters at the end of the branches [7, 8]. The tree is cauliflorous with 18-68 flowers in panicles that form on the trunk and other branches. The flowers are heterotristylous with petal 10-30 cm long, yellowish green to reddish purple [9].

(b). Carica papaya (Papaya)

Class : Dicotyledon

Order : Brassicales

Family :Caricaceae

Papaya is a giant herbaceous plant resembling a tree but not woody, in the caricaceae family that originated in the Central America and is now grown in tropical areas worldwide for its large sweet melon like fruits. The papaya plant has a hollow, green, purple stem and can grow 1.8-3 $\mathrm{m}$ in a year, eventually reaching heights of 6-9m.The long petioled leaves, which may be 30-105 cm long and 30- $60 \mathrm{~cm}$ wide. Both leaves and stems contain large amount of white, milky latex.

Aqueous leaf extracts preparation:

Collected leaves were surface sterilized using distilled water. 15 gram of leaves was ground in a mortar and pestle with $10 \mathrm{ml}$ of distilled water. The extract was then filtered using Whatman filter paper. This filtrate was then used for further phytochemical analysis.

Preliminary phytochemical screening of aqueous leaf extracts:

(a). Test for Terpenoids

To $5 \mathrm{ml}$ extract $2 \mathrm{ml}$ of chloroform and $3 \mathrm{ml}$ of sulphuric acid were mixed. Formation of reddish brown colour indicates the presence of terpenoids.

(b). Test for saponins (Frothing test):

$5 \mathrm{ml}$ of the aqueous extract was shaken vigorously with $20 \mathrm{ml}$ of distilled water. Formation of persistent froth indicates the presence of saponins.

(c).Test for phenols:

A few drops of alcoholic ferric chloride solution were added to the aqueous extract. Formation of violet, bluish green or bluish black colour indicated the presence of phenols.

(d).Test for steroids:

A few drops of concentrated sulphuric acid were added to a little amount of extract and was shaken for few minutes; the development of red or brown colour indicates the presence of steroids.

(e). Test for tannins:

Few drops of $1 \%$ ferric chloride solution were added to $2 \mathrm{ml}$ of the extract. Occurrence of a blue- black, green or blue green precipitate indicates the presence tannins.

(f). Test for coumarins (colour test):

A small amount of extract was mixed with methanol or ethanol on adding alcoholic potassium hydroxide or sodium hydroxide gives a yellow colour which disappears on adding concentrated hydrochloric acid. 
(g).Test for protein detection (xanthoprotein test):

A small amount of the extract was added with $0.5 \mathrm{ml}$ of concentrated nitric acid. Appearance of white or yellow precipitate revealed the presence of protein.

(h).Test for quinines:

To the extract, sodium hydroxide was added. Formation of blue, green or red colour indicated the presence of quinines.

(i)Test for Anthraquinones :

The extract was shaken with aqueous ammonia. Formation of pink, violet or red colour indicates the presence of anthraquinones.

(j)Test for flavonoids:

$1 \mathrm{ml}$ of aqueous sodium hydroxide was added to $1 \mathrm{ml}$ of test solution. Formation of yellow colour indicates the presence of flavonoids.

2. Fungal isolation from paddy seeds and roots:

Seeds and roots of paddy were used for fungal isolation. Seeds were collected from moncompu Rice Research Station, Alappuzha and roots were collected from Poomkavu region of Pathanamthitta District of Kerala.

Preparation of Potato Dextrose Agar (PDA) Medium [10]:

PDA is a general purpose medium for cultivation, sporulation and pigmentation of pathogenic and non-pathogenic fungi.

Composition of PDA medium:

$\begin{array}{ll}\text { Potato } & -200 \mathrm{gm} \\ \text { Dextrose } & -20 \mathrm{gm} \\ \text { Agar } & -20 \mathrm{gm}\end{array}$

Distilled water - $1 \mathrm{~L}$

$200 \mathrm{gm}$ of potato sliced into small pieces, boil the sliced potato in $500 \mathrm{ml}$ distilled water for 30 minutes in a vessel or pressure cooker for 20 minutes and decant through cheese clothes. Mix 20 gm of agar with $500 \mathrm{ml}$ distilled water and boil in a cooker for 30 minutes. Add 20 gm of dextrose into potato extract. Mix molten agar with potato agar mixture and make the volume to $1 \mathrm{~L}$ with distilled water. Final pH of the medium was adjusted to 6 and then autoclave the medium. Just before adding the sterile PDA medium into the sterile petriplate, the medium was supplemented with ampicillin to inhibit the bacterial growth. The sterile petriplates were then added with sterile PDA (Potato Dextrose Agar) medium inside the inoculation chamber.

Inoculation of paddy seeds and roots to PDA medium:

The collected seeds and root pieces were surface sterilized using tap water. Extreme growing tips of roots and seed coat removed seeds were used for inoculation. Such plant materials were inoculated in each sterilized petriplates (4 seeds and root pieces /plate) at equal distance. Total six plates were inoculated. Then the plates were sealed with parafilm and incubated at room temperature for fungal growth.

Fungal isolation and pure culture development:

Most of the fungal growth was initiated on $4^{\text {th }}$ and $5^{\text {th }}$ day of inoculation. The growing colonies of fungus were observed in different colours. They were subcultured for pure culture development. Subculturing was done by transferring small mycelia plugs from the colony margins to sterilized plates for purification and identification [11]. Each fungal isolates were transferred to new plates containing PDA medium using sterilized needles for pure culture development. Pure culture was obtained by subculturing three times [12].

Identification of fungi:

The identification was done by observations and findings of the pure culture on the basis of their colony morphology and spore characteristics $[13,14]$. Identification of different fungi was done with the help of slides prepared by direct mount from the culture. For preparation, the fungal hyphae were mounted on a slide, stained with Lacto phenol cotton blue to detect fungal structures [15]. The slides were examined under Lx400 trinocular microscope and photographs were taken by using BioLinkz Cmos Camera (3.0m pixels) attached to the microscope. All isolates of fungi were grown quickly, usually covering the whole surface of the petridish and showed profuse sporulation on PDA medium.

3. Disc diffusion method [16]:

Antifungal properties of aqueous leaf extracts were screened and measured through disc diffusion method. The thick extract of fresh leaves of bilimbi and papaya in water were prepared and were used for antifungal screening. Antifungal activities of leaf extracts were tested against fungal pathogens Curvularia, Penicillium and Cylindrocarpon which were isolated from seed and root of paddy. In disc diffusion method dried and sterilized filter paper discs ( $0.6 \mathrm{~mm}$ radius) were impregnated with known amounts of extract (about $3 \mathrm{mg}$ ). Disc containing extract were placed on the petriplate which is uniformly streaked with pure 
culture of tested fungus. Streaking is done using sterilized ear buds. These plates are then sealed with parafilm and kept at room temperature to allow maximum diffusion of the extract.

Determination of diameter of zone of inhibition:

The extracts having antimicrobial activity inhibited the growth of the microorganisms and a clear distinct zone of inhibition was visualized surrounding the discs. The intensity of antifungal activity of the extracts was determined by measuring the diameter of zone of inhibition expressed in mm [17]. Diameter of inhibition was measured and graded as ' + ' if the zone was below $6 \mathrm{~mm}$, ' ++ ' if the zone ranged from 6-10 $\mathrm{mm}$ and ' +++ ' if it was above $10 \mathrm{~mm}$ and '-' indicate no action.

\section{RESULT}

Preliminary phytochemical screening of aqueous leaf extracts were conducted and detected the presence of flavanoids, saponins, coumarins and steroids from bilimbi leaf, terpenoids, saponins, coumarins and steroid from papaya leaf (Table:1). Fungal pathogens were isolated from paddy root and seed using PDA medium, which include Rhizopus, Aspergillus, Cylindrocarpon, Penicillium and Curvularia (Table:2). Disc diffusion method was used to measure the antifungal property of leaf extracts on 3 selected fungal genera such as Cylindrocarpon, Penicillium and Curvularia which were used as test organisms.

The extracts having antimicrobial activity has varied diameter of zone of inhibition among tested organisms. Bilimbi leaf has antifungal activity against Cylindrocarpon, Penicillium with zone of inhibition of 10mm, and 5mm respectively and no markable activity against Curvularia. Papaya leaf has antifungal activity against Cylindrocarpon, Penicillium and Curvularia with zone of inhibition of $12 \mathrm{~mm}, 5 \mathrm{~mm}$ and $15 \mathrm{~mm}$ respectively (Table: 3 \& Graph:1).

Table No.1: Preliminary phytochemical screening of aqueous leaf extracts

\begin{tabular}{|l|l|c|c|}
\hline Sl.No & Phytochemicals & Bilimbi & Papaya \\
\hline 1 & Flavonoids & + & - \\
\hline 2 & Saponins & + & + \\
\hline 3 & Terpenoids & - & + \\
\hline 4 & Phenols & - & - \\
\hline 5 & Tannins & - & - \\
\hline 6 & Coumarins & + & + \\
\hline 7 & Steroids & + & + \\
\hline 8 & Proteins & - & - \\
\hline 9 & Anthraquinones & - & - \\
\hline 10 & Quinine & - & - \\
\hline
\end{tabular}

Table No.2: List of fungus isolated from paddy root and seed.

\begin{tabular}{|l|l|l|l|l|}
\hline Sl. No. & Plant part used & Name of the fungus & Subdivision & Colony morphology \\
\hline \multirow{4}{*}{1} & \multirow{4}{*}{ Paddy seed } & Rhizopus & Zygomycotina & White \\
\cline { 3 - 5 } & & Aspergillus & Ascomycotina & Yellow brown \\
\cline { 3 - 5 } & & Cylindrocarpon & Ascomycotina & Orange \\
\cline { 3 - 5 } & & Penicillium & Ascomycotina & Dark green \\
\cline { 3 - 5 } & & Curvularia & Deuteromycotina & Velvety black \\
\hline 2 & Paddy root & Aspergillus & Ascomycotina & Yellow brown \\
\cline { 3 - 5 } & & Penicillium & Ascomycotina & Dark green \\
\hline
\end{tabular}

Table No.3: Antifungal activity of leaf extracts \& diameter of zone of inhibition.

\begin{tabular}{|l|l|c|c|}
\hline Leaf Extract & Fungus & Effect & Zone of inhibition (mm) \\
\hline \multirow{5}{*}{ Bilimbi } & Cylindrocarpon & ++ & 10 \\
\cline { 2 - 4 } & Penicillium & + & 5 \\
\cline { 2 - 4 } & Curvularia & - & - \\
\hline \multirow{5}{*}{ Papaya } & Cylindrocarpon & ++ & 5 \\
\cline { 2 - 4 } & Penicillium & +++ & 15 \\
\cline { 2 - 4 } & Curvularia & ++ & 5 \\
\hline
\end{tabular}


Diameter of inhibition was measured and graded as '+' if the zone was below $6 \mathrm{~mm}$, ' ++ ' if the zone ranged from $6-10 \mathrm{~mm}$, ' +++ ' if it was above $10 \mathrm{~mm} \&$ '-' indicate no action.

Graph No: 1 Diameter of zone of inhibition of pathogenic fungi.

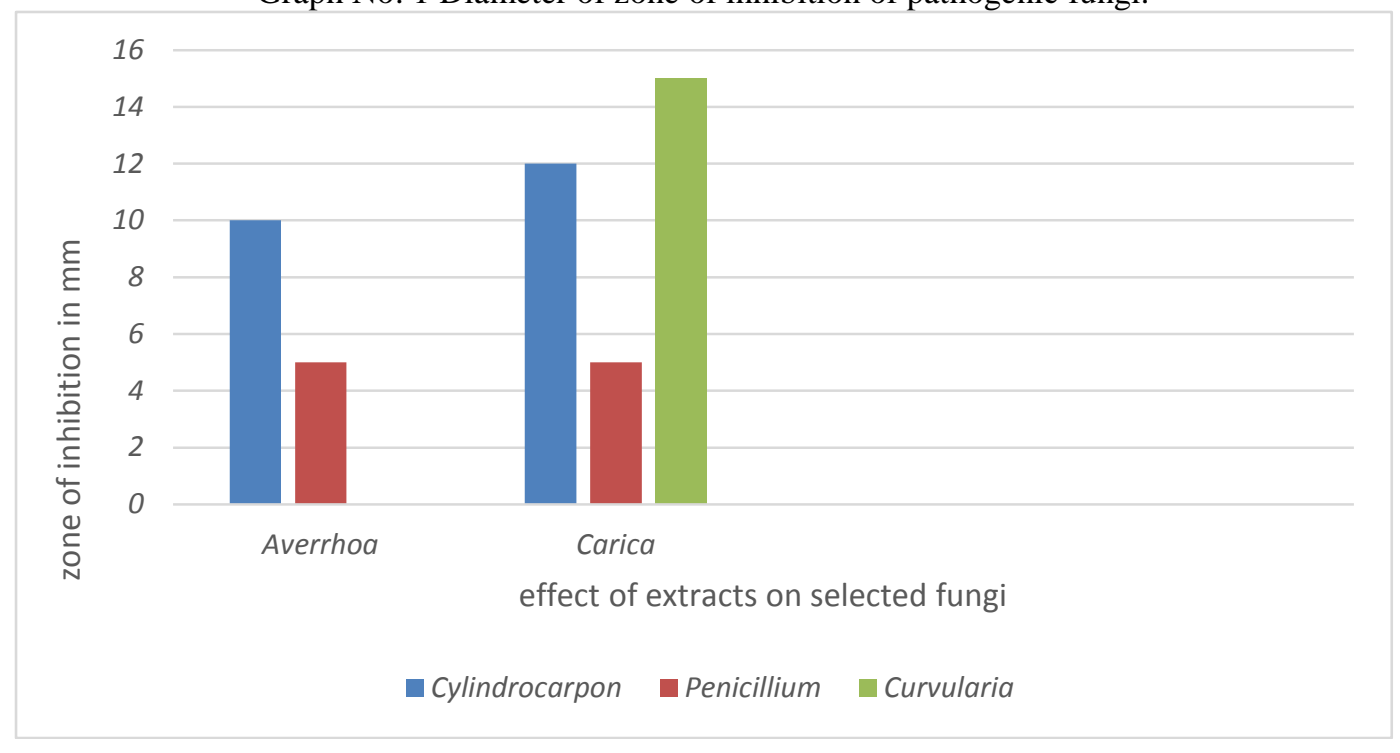

\section{DISCUSSION}

The diversity of phytochemicals among plant material was well established. The different phytoconstituents present in the plants were responsible for their antimicrobial activity. Phytochemical screening of aqueous extracts revealed the presence of flavanoids, saponins, coumarins and steroids from bilimbi leaf, terpenoids, saponins, coumarins and steroid from papaya leaf. We isolated 5 genera of fungus from root and seed of paddy plant. The fungi isolated from paddy seed were Rhizopus, Aspergillus, Cylindrocarpon, Penicillium and Curvularia. And the fungus isolated from paddy root includes Aspergillus and Penicillium. Disc diffusion method was used to measure the antifungal property of leaf extracts on 3 selected fungal genera such as Cylindrocarpon, Penicillium and Curvularia which were used as test organisms. Bilimbi leaf has antifungal activity against Cylindrocarpon, Penicillium with zone of inhibition of $10 \mathrm{~mm}$, and $5 \mathrm{~mm}$ respectively and no markable activity against Curvularia. Papaya leaf has antifungal activity against Cylindrocarpon, Penicillium and Curvularia with zone of inhibition of $12 \mathrm{~mm}, 5 \mathrm{~mm}$ and $15 \mathrm{~mm}$ respectively. The highest level of antifungal activity was recorded in papaya leaf extract which was active against all tested organisms that may be due to the different types of phytochemicals.

Antifungal activity of plant and plant products emerge clearly every day. Scientist can develop new molecules using useful plant metabolites to combat the emerging issues of drug resistance. Numerous studies are progressing in all parts in this direction.

\section{CONCLUSION}

Currently the search for natural products with novel uses particularly related to disease and pest management is very active. Plants offer thousands of new molecules. The presence of different bioactive compounds among plants makes it as potent bioresource for future research to combat drug resistance since it has commendable antimicrobial properties. Antimicrobial substances which are obtained from plants have no side effects and are ecofriendly in nature, thus giving a significant advantage.

The present study was significant which has witnessed the phytochemical and antifungal property of leaf extract against the tested microorganisms. The highest level of antifungal activity was recorded in papaya leaf extract which was active against all tested organisms that may be due to the presence of phytochemicals. Plant extracts with antimicrobial properties contain a wide spectrum of secondary metabolites such as alkaloids, saponins, glycosides, tannins, flavonoids and terpenoids. The concentration of these bioactive compounds in each plant species depends on the environmental conditions and pathosystem[18]. These active principles may have acted alone or in combination to inhibit the growth of fungal and bacterial strains. 
The observed results were significant, as drug resistant pathogens are emerging globally with a myriad of clinical manifestations. Plant metabolites are strong candidate contribute to develop new leads, combat the emerging issues of drug resistance. However, more detailed investigations including clinical trials are essential in this regards.

\section{REFERENCE}

[1]. O. P. Sharma, "Fungi and allied microorganisms", McGraw Hill Education Pvt. Ltd, India pp. $280,1989$.

[2]. M. A. Chinju, M. T. Tincy, "Emerging fungal contaminants isolated and identified from raw fennel seeds", International Journal of Scientific Research in Biological Sciences, Vol.5, Issue.3, pp.32-35, 2018.

[3]. J. Loeffler, D. Stevens, “Antifungal drug resistance”, Clinical Infectious Diseases, Vol.36, pp. 531-541, 2003.

[4]. A. D. Rocha, A. B. de Oliveira, J. D.de souza Filho, J. A. Lombardi, F.C. Braga, "Antifungal constituents of Clytostoma ramentaceum and Mansoa hirsute", Phytotherapy Research, Vol.18, pp.463-467, 2004.

[5]. O. S. Koushik, P. S.Babu,, R. Karthikeyan, "Phytochemical screening and evaluation of antifungal activity on the seed extracts of Annona squamosa (L) and Manilkara zapota (L)", CIB Tech Journal of Biotechnology,Vol. 6, Issue.1, pp. 811, 2017.

[6]. V.L. De Lima, E. D. Milo, L.D. Lima, "Physiochemical characteristics of bilimbi (Averrhoa bilimbi L.)", Revista Brasileira de Psciquiatria Vol.23, pp.421-423, 2001.

[7]. Orwa, A.Mutua, R.Kindt, R.Jamnadass, S.Anthony, Agroforestree Database: a tree reference and selection guide, 2009.

[8]. T.K.Lim,"Edible Medicinal and non medicinal plants", Springer, Netherlands, pp.867-878, 2012.

[9]. F.R. Ganders, “The biology of heterostyly”, New Zealand Journal of Botany, Vol. 17, pp. 607-635, 1979.

[10]. F.P Downes, K. Ito, "Compendium of Methods for the microbiological examination of foods",APHA, Washington, D.C, 2001.

[11]. H. Mokhtar, A. Dehimat, "Contribution in isolation and identification of some pathogenic fungi from wheat seeds and evaluation of antagonistic capability of Trichoderma harzianum against those isolated fungi in vitro", Agriculture and Biology Journal of North America, Vol.4, Issue.2, pp.145-154, 2013.

[12]. C. Booth, "Fusarium laboratory guide to the identification of the Major species", Common wealth Mycological Institute, England, pp. 58, 1977.

[13]. S. Ronhede, B. Jenesen, S. Rosendahl, B. B. Kragelund, R. K. Juhler, J. Amand, "Hydroxylation of the herbicide isoproturon by fungi isolated from agricultural soil”, Applied and Environmental microbiology ,Vol.71, Issue.12, pp.7927-7932, 2005.

[14]. P. N. Rajankar, D. H. Tambekar, S.R. Wate , "Study of phosphate solubilization efficiencies of fungi and bacteria isolated from saline belt of purna river basin”, Research Journal of Agriculture and Biological Sciences, Vol.3 ,Issue. 6, pp.701-703, 2007.

[15]. P.K. Basu, "Production of Chlamydospore of Phytophthora megasperma and their possible role in primary infection and survival in soil", Canadian Journal of Plant pathology, Vol. 2, pp. 70-75, 1980.

[16]. K. Vijay, S. Sriram, "In vitro antibacterial activity in seed extracts of Manilkara zapota, Annona squamosa and Tamarindus indica”. Biological Research, Vol. 43, pp.165-168, 2010.

[17].F. Nasrin , I. J. Bulbul, Y. Begum, S. Khanum, "Invitro antimicrobial and cytotoxicity screening of nhexane,chloroform and ethyl acetate extracts of Lablab purpureus (L.) leaves". Agriculture and Biology Journal of North America, Vol. 3, Issue.2, pp. 43-48, 2012.

[18].S. Balakumar, S. Rajan, T.Thirunalasundari, S. Jeeva,S, “ Antifungal Activity of Aegle Marmelos (L.) Correa (Rutaceae).Leaf extract on dermatophytes”. Asian Pacific Journal of Tropical Biomedicine, Vol. 1, issue.4, pp. 309 - 312, 2011.

\section{AUTHORS PROFILE}

Chinju Merin Abraham, awarded her M.Sc Botany and M.Phil and currently working as a Lecturer in Department of Botany, Catholicate College, Pathanamthitta, Kerala, India. Soumya Prasad awarded her M.Sc Botany from Department of Botany, Catholicate College, Pathanamthitta, Kerala, India. 